\title{
BMJ Open Knowledge, attitudes and preferences of palliative and end-of-life care among patients with cancer in mainland China: a cross-sectional study
}

\author{
Qinqin Cheng, ${ }^{1}$ Yinglong Duan, ${ }^{2}$ Hongling Zheng, ${ }^{3}$ Xianghua $X u,{ }^{4}$ Khalid Khan, ${ }^{3}$ \\ Jianfei Xie, ${ }^{5}$ Yongyi Chen (iD) ${ }^{6}$
}

To cite: Cheng Q, Duan Y, Zheng $\mathrm{H}$, et al. Knowledge, attitudes and preferences of palliative and end-of-life care among patients with cancer in mainland China: a crosssectional study. BMJ Open 2021;11:e051735. doi:10.1136/ bmjopen-2021-051735

- Prepublication history for this paper is available online. To view these files, please visit the journal online (http://dx.doi. org/10.1136/bmjopen-2021051735).

Received 26 March 2021 Accepted 03 September 2021

Check for updates

(C) Author(s) (or their employer(s)) 2021. Re-use permitted under CC BY-NC. No commercial re-use. See rights and permissions. Published by BMJ.

${ }^{1}$ Pain Management Department, Hunan Cancer Hospital, Changsha, Hunan, China ${ }^{2}$ Emergency Department, The Third Xiangya Hospital, Central South University, Changsha,

China

${ }^{3}$ Xiang Ya Nursing School of Central South University, Changsha, Hunan, China ${ }^{4}$ Health Management Center, Hunan Cancer Hospital, Changsha, Hunan, China ${ }^{5}$ Nursing Department, The Third Xiangya Hospital, Central South University, Changsha, China ${ }^{6}$ Admin Office, Hunan Cancer Hospital, Changsha, Hunan, China

Correspondence to Dr Yongyi Chen; 414700595@qq.com

\section{ABSTRACT}

Objectives This study aimed to investigate the knowledge and attitudes of patients with cancer of palliative care and their preferences regarding end-of-life care in mainland China.

Design A cross-sectional study.

Setting This study was conducted in a tertiary cancer hospital.

Participants Two hundred forty-seven patients with cancer were recruited and consented to fill out the questionnaires.

Outcome measures The participants' knowledge and attitudes of palliative care and their preferences of end-of-life care involving place of care, place of death, truth disclosure and treatments during end-of-life were measured.

Results In total, 239 questionnaires were valid. The vast majority of patients with cancer (81.2\%) had never heard about palliative care or related policies, and only a few of them (5.8\%) had somewhat or totally understanding of palliative care. Most participants $(75.3 \%)$ had supportive attitudes towards palliative care. In terms of preferences for end-of-life care, most patients with cancer preferred to be cared for at home at the end of their life and to die at home. The majority of patients with cancer $(65.7 \%)$ wanted to know their diagnosis or prognosis of the disease, regardless of the type of disease. More than half of the participants (54\%) wished to improve their quality of life rather than prolong their life expectancy. More than a third of the patients with cancer preferred to entrust a family member or agent to sign medical decision agreements for them.

Conclusions It is essential for healthcare providers to improve the understanding of patients with cancer of palliative care and be aware of the end-of-life care preferences of patients with cancer, in order to provide support that enables patients with cancer to receive endof-life care that is accordant with their wishes.

\section{INTRODUCTION}

Cancer is the leading cause of death in China, with an increasing incidence every year. ${ }^{1}$ According to statistics, there are approximately 4.3 million new cancer cases and 2.9 million cancer deaths every year in China,
Strengths and limitations of this study

- This is a cross-sectional study on the knowledge, attitudes and preferences of palliative and end-of-life care issues, which have been scarcely investigated among mainland Chinese patients with cancer.

- We recruited patients with cancer by convenience sampling from a single hospital, which may limit the generalisability of the results.

- Some choices in the questionnaire involved hypothetical situations, so results can not necessarily present actual preferences when the patients with cancer come to the terminal stage.

- Only descriptive statistics were conducted, and the factors associated with the knowledge, attitudes and preferences of palliative and end-of-life care were not analysed.

accounting for $24 \%$ of the new cases and $30 \%$ of cancer deaths worldwide. ${ }^{2}$ China has a lower cancer incidence but a $30 \%$ and $40 \%$ higher cancer mortality rate than the UK and the USA. ${ }^{1}$ Therefore, patients with cancer compose the majority of subjects receiving palliative care and end-of-life (EOL) care in China.

Palliative care began in 1988 and has been developing for more than 30 years in mainland China. ${ }^{3}$ According to the 2015 Quality of Death Index, China ranked 71st out of 80 countries and regions in terms of quality of palliative care. ${ }^{4}$ In order to promote the development of palliative care, the government began issuing a series of policies and guidance documents in 2016..$^{5-8}$ However, despite the policy, palliative care subjects are very critical in the development of palliative care as a whole. As the main subjects of palliative care in mainland China, the knowledge and attitudes of patients with cancer towards palliative care are critical factors that influence their willingness to accept it. ${ }^{9}$ Moreover, 
their knowledge and attitudes may also affect their decisions in EOL. ${ }^{10}$ Hence, an increased understanding of the knowledge and attitudes of patients with cancer towards palliative care is important, as it can provide references to further tailor intervention. In 2017, a survey was conducted to investigate outpatients' knowledge and attitudes regarding hospice care in two hospitals in Beijing, China. Results showed that patient awareness of hospice care was still low. ${ }^{11}$ However, these results could not be generalised for other places in mainland China. Moreover, this also could not reflect the status of current knowledge and attitudes of patients with cancer towards palliative care, because a few years have passed. Thus, it is essential to conduct another study among patients with cancer.

EOL care is the support and care provided in the terminal phase of life. ${ }^{12}$ Understanding the preferences of patients with cancer of EOL care could help healthcare providers know more about their concerns, which is a prerequisite for EOL care complying with patients' preferences. ${ }^{13}$ Further research is needed to explore patients' preferences of EOL care, which should also not be restricted to patients who will be dying. ${ }^{14}$ Therefore, talking to patients with cancer about EOL care preferences in the early stages is also a requirement.

Up until now, EOL preferences among patients with cancer have been explored in some countries and regions. ${ }^{15-21}$ These studies identified the preferences of patients with cancer for EOL treatment, communication, decision-making and place of care and death. Results showed that more patients with cancer preferred comfort care and maintaining their quality of life in EOL. ${ }^{19} 20$ Some patients with cancer expressed their preference to die in a state of unconsciousness induced by drugs. ${ }^{18}$ Most patients with cancer would like to be informed of their diagnosis and prognosis, ${ }^{15} 17$ but more patients with cancer in South Africa did not want to know their prognosis. ${ }^{20}$ Regarding the preferred place of care and death, a larger proportion of patients with cancer chose to be at home ${ }^{16-20}$ but patients with cancer in Pakistan preferred hospital-based care and death. ${ }^{15}$ Therefore, we can conclude that different cancer populations have various preferences of EOL care under different cultural contexts.

EOL care practice in mainland China is different from western countries. The families are often involved in EOL decision-making in mainland China. ${ }^{22}$ This may lead to situations where patients with cancer receive treatments that are inconsistent with their own wishes. Therefore, it is crucial to know the EOL care preferences of patients with cancer from their perspectives. There has been little research conducted on EOL care preferences among mainland Chinese patients with cancer. Given that patients with cancer in mainland China constitute a great portion of cancer populations worldwide, it is essential to investigate the knowledge, attitudes and preferences of palliative and EOL care among mainland Chinese patients with cancer. Therefore, the present study aimed to (1) investigate the knowledge and attitudes of patients with cancer of palliative care and (2) explore their preferences for EOL care, involving place of care and death, truth disclosure and treatment.

\section{METHODS}

\section{Research design}

This was a descriptive, cross-sectional study carried out among mainland Chinese patients with cancer.

\section{Setting and participants}

This study was conducted in a tertiary cancer hospital in Hunan province, China. This hospital built the palliative care unit and has initiated palliative care service since 2013. In the palliative care unit, the patients are provided with symptom management, comfort care and psychological and spiritual support by the palliative care multidiscipline team. The patients with cancer in the other units of the hospital can also be referred to the palliative care multidiscipline team, if necessary. Potential participants in this hospital were invited to participate in the survey by convenience sampling from all patients with cancer who were hospitalised between December 2019 and January 2020. Inclusion criteria were (1) diagnosed with cancer, (2) aged $\geq 18$ years with competent language communication abilities, (3) informed of his/her disease and (4) voluntarily participated in the study under the principle of informed consent. Exclusion criteria were (1) nonresponsive (did not complete the questionnaire) and (2) mentally unstable or having a major mental disorder.

\section{Data collection}

We used the questionnaire adapted from the one developed by Wen-Yu Hu. ${ }^{9}$ One of our coauthors obtained permission to use and adapt the questionnaire. The original questionnaire was in traditional Chinese. There is little difference between the semantic expressions and formats of traditional Chinese and simplified Chinese, so we transformed the traditional Chinese into simplified and made some revisions to the expressions to make them semantically easier to be understood by mainland Chinese people. The structured questionnaire included three sections: general information, knowledge and attitudes towards palliative care and preferences of EOL care.

Section 1 included 14 items to collect participants' basic information, including gender, age, education, marital status and occupation, etc. In Section 2, there were 11 questions mainly focusing on patients' understandings and attitudes towards palliative care. Six questions were asked about understandings of palliative care, resuscitation, do not resuscitate (DNR), advance care planning and policies on palliative care. Five questions were used to assess the attitudes towards palliative care, DNR and signing on medical decision agreements. Section 3 aimed to collect patients' preferences of EOL care and involved four aspects: preferred place of care, preferred place of death, preferences of truth disclosure and preferred 
treatment. In the preferred place of care part, there were two items mainly assessing the preferred place of care and its relationship to medical insurance. In the preferred place of death part, there were four items asking participants about their choices and reasons for choosing their preferred place of death. As for truth disclosure, three items were used to evaluate the willingness to be informed of the diagnosis and terminal status of the disease. In the last part, two questions were used to assess participants' choices about the treatments and medical decisions in EOL.

\section{Data collection procedures}

Before starting the investigation, we trained the data collectors in terms of what palliative care is and how to interpret the purpose, process and potential benefits/ harms to the participants to ensure the quality of data collection. Then, the data collectors introduced the definition of palliative care and the relevant research information to the potential participants and invited them to participate in the study. We obtained oral informed consent from all the participants who wanted to fill in the questionnaires. After that, the participants filled out the survey anonymously. In total, 247 participants were recruited in this study after we obtained informed consent. All questionnaires were completed by the participants themselves with no interference.

\section{Research governance}

The study had been approved by the institutional review board of behavioural and nursing research in the School of Nursing of Central South University (12019014). The study strictly followed the principles of the Helsinki Declaration. All data in this study were kept secure and would not be accessible to any other people.

\section{Data analysis}

After collection, all data were inputted by one of the coauthors and checked by another one. The data were analysed by IBM SPSS V.18.0. As there were no scores being summed up from these data, appropriate descriptive statistics were used to describe the participants' general information, knowledge and attitudes towards palliative care and preferences of EOL care. Means and SD were used to describe continuous variables (the participants' age and time since being diagnosed). Frequency (n) and percentages $(\%)$ were used to described the categorical variables (participants' other general information, each item of the knowledge and attitudes towards palliative care and preferences of EOL care). Regarding the missing data, we have removed the cases with missing data $>20 \%$. For cases with a few missing values, we kept these data for analysis, as these participants also provided important information about other items.

\section{Patient and public involvement}

Patients and/or the public were not involved in the design, conduct, reporting or dissemination plans of this research.
Table 1 Participants' basic information $(n=239)$

\begin{tabular}{|c|c|c|}
\hline Variables & $N$ & $\%$ \\
\hline Age & \multicolumn{2}{|c|}{$49.63 \pm 11.65($ mean $\pm S D)$} \\
\hline \multicolumn{3}{|l|}{ Gender } \\
\hline Male & 104 & 43.5 \\
\hline Female & 135 & 56.5 \\
\hline \multicolumn{3}{|l|}{ Education level } \\
\hline Primary school and below & 75 & 31.4 \\
\hline Middle school & 78 & 32.6 \\
\hline High school & 41 & 17.2 \\
\hline Above high school & 45 & 18.8 \\
\hline \multicolumn{3}{|l|}{ Marital status } \\
\hline Married & 215 & 90.0 \\
\hline Divorced/widowed & 12 & 5.0 \\
\hline Unmarried/others & 12 & 5.0 \\
\hline \multicolumn{3}{|l|}{ Residence } \\
\hline Rural area & 154 & 64.44 \\
\hline Urban area & 85 & 35.56 \\
\hline \multicolumn{3}{|l|}{ Religiosity } \\
\hline None & 215 & 90.0 \\
\hline Yes & 24 & 10.0 \\
\hline \multicolumn{3}{|l|}{ Tumour site } \\
\hline Head and neck & 69 & 28.9 \\
\hline Nervous & 3 & 1.3 \\
\hline Thorax & 57 & 23.8 \\
\hline Abdominal & 18 & 7.5 \\
\hline Digestive & 30 & 12.6 \\
\hline Genital & 24 & 10.0 \\
\hline Urinary & 8 & 3.3 \\
\hline Bone & 3 & 1.3 \\
\hline Lymphatic/haematological & 9 & 3.8 \\
\hline Others & 18 & 7.5 \\
\hline Time since diagnosed & \multicolumn{2}{|c|}{$6.61 \pm 6.11($ mean $\pm S D)$} \\
\hline \multicolumn{3}{|c|}{ Whether or not have discussed EOL treatment } \\
\hline No & 194 & 81.2 \\
\hline Yes & 45 & 18.8 \\
\hline
\end{tabular}

EOL, end-of-life.

\section{RESULTS}

\section{Participants' basic information}

In this study, a total of 247 patients with cancer consented to participate in the survey and filled out the questionnaires. After removing the questionnaires with missing data $>20 \%, 239(96.8 \%)$ valid questionnaires still remained. Table 1 shows the basic information of the 239 participants. The mean age of the participants was $49.63(\mathrm{SD}=11.65)$ years old. The majority of patients with cancer $(56.5 \%)$ were women, and the mean time since diagnosis was $6.61(\mathrm{SD}=6.11)$ months. 
Table 2 Knowledge of palliative care $(n=239)$

\begin{tabular}{lll}
\hline Items & $N$ & $\%$ \\
\hline Knowledge &
\end{tabular}

Whether you have heard about palliative care or related policies

\begin{tabular}{|c|c|c|}
\hline No & 194 & 81.2 \\
\hline Yes & 45 & 18.8 \\
\hline \multicolumn{3}{|l|}{ Understanding palliative care } \\
\hline Totally do not understand & 59 & 24.7 \\
\hline Do not understand & 118 & 49.4 \\
\hline Neutral & 48 & 20.1 \\
\hline Somewhat understand & 13 & 5.4 \\
\hline Totally understand & 1 & 0.4 \\
\hline \multicolumn{3}{|c|}{ Understanding cardiopulmonary resuscitation* } \\
\hline Totally do not understand & 25 & 10.5 \\
\hline Do not understand & 97 & 40.6 \\
\hline Neutral & 67 & 28.0 \\
\hline Somewhat understand & 46 & 19.2 \\
\hline Totally understand & 3 & 1.3 \\
\hline \multicolumn{3}{|l|}{ Understanding DNR* } \\
\hline Totally do not understand & 27 & 11.3 \\
\hline Do not understand & 108 & 45.2 \\
\hline Neutral & 65 & 27.2 \\
\hline Somewhat understand & 37 & 15.5 \\
\hline Totally understand & 1 & 0.4 \\
\hline \multicolumn{3}{|c|}{ Understanding advance care planning* } \\
\hline Totally do not understand & 40 & 16.7 \\
\hline Do not understand & 138 & 57.7 \\
\hline Neutral & 44 & 18.4 \\
\hline Somewhat understand & 15 & 6.3 \\
\hline Totally understand & 0 & 0 \\
\hline \multicolumn{3}{|c|}{ Understanding policies on palliative care } \\
\hline Totally do not understand & 50 & 20.9 \\
\hline Do not understand & 136 & 56.9 \\
\hline Neutral & 37 & 15.5 \\
\hline Somewhat understand & 16 & 6.7 \\
\hline Totally understand & 0 & 0 \\
\hline
\end{tabular}

${ }^{*}$ The total number of participants was not 239 , because there were missing data in this item.

DNR, do not resuscitate.

\section{Knowledge and attitudes towards palliative care}

Table 2 shows the participants' knowledge of palliative care. Among the 239 patients with cancer, the majority of them $(81.2 \%)$ had never heard of palliative care or the related policies. For those who had heard about palliative care or the related policies, they received information from newspapers, periodicals, social media, leaflets, health medical staff or hospital bulletin boards. Only $5.8 \%$ of the participants had somewhat of an understanding of palliative care. Less than $10 \%$ of the participants had somewhat of an understanding of advance care planning and policies on palliative care. Regarding cardiopulmonary resuscitation and DNR, a limited number of participants had some understanding or total understanding.

Most participants (75.3\%) held supportive attitudes towards palliative care. When asked about their preferences when signing EOL medical decision agreements, most of the participants $(77.4 \%)$ claimed that they might sign any EOL medical decision agreements in advance when conscious and competent. One hundred fifty-eight (66.1\%) participants agreed that they might sign agreements to not undergo intensive rescuing when at the terminally ill stage. However, if their relatives were ill and came to the terminally ill stage, more participants $(59.4 \%)$ held a different attitude. Other detailed information is presented in table 3 .

\section{EOL care preferences}

Table 4 displays the results of participants' preferences of EOL care. Most $(\mathrm{n}=157,65.7 \%)$ of the participants preferred to be cared for at home in the EOL, and $79.1 \%$ $(n=189)$ preferred to die at home. Even when they were treated in the hospital, most of them $(84.9 \%)$ indicated that they would like to come back home when dying. 'Home is the most familiar place' $(n=145,71.4 \%)$ and 'hoping to be accompanied by families' ( $\mathrm{n}=157,77.3 \%$ ) were the most common reasons for choosing home as the place of death. When asked about why they would not choose to die at home, the majority of the respondents did not want to cause their families any distress $(n=25$, $75.8 \%$ ). Regarding truth disclosure, $65.7 \%$ of patients with cancer wanted to know their diagnosis or prognosis of the disease regardless of the type of disease, and $74.1 \%$ of them wished to know the terminal stage of their disease when they came to EOL. As for preferred treatments in EOL, more than half of the participants $(54 \%)$ wished to improve their quality of life rather than prolong their life expectancy in EOL care. A small portion (13.8\%) of patients would not sign any medical decision agreements in written or in oral form. More than a third preferred to entrust a family member or agent to sign medical decision agreements for them.

\section{DISCUSSION}

In this study, we explored the knowledge, attitudes and preferences of palliative and EOL care issues among patients with cancer in mainland China. The findings will not only provide deep insight into the thoughts of patients with cancer on EOL care but also have implications for caring for terminally ill patients with cancer.

In the current study, the majority of patients with cancer had a limited understanding of palliative care, advance care planning and cardiopulmonary resuscitation and DNR, which was similar to previous findings. ${ }^{11}$ This could be explained by the initial stage of palliative 
Table 3 Attitudes towards palliative care $(n=239)$

\begin{tabular}{lrr} 
Items & N & \multicolumn{1}{c}{$\%$} \\
\hline Attitude towards palliative care* & & \\
Completely agree & 8 & 3.3 \\
Agree & 172 & 72.0 \\
Disagree & 44 & 18.4 \\
Completely disagree & 2 & 0.8
\end{tabular}

Whether DNR is ethically the same as removing the CPR already performed*

$\begin{array}{lrl}\text { Yes } & 38 & 15.9 \\ \text { No } & 64 & 26.8 \\ \text { Not sure } & 136 & 56.98\end{array}$

Whether or not you will sign any EOL medical decision agreements in advance when you are conscious and competent $^{\star}$

\begin{tabular}{|c|c|c|}
\hline Highly possible & 17 & 7.1 \\
\hline Possible & 168 & 70.3 \\
\hline Impossible & 47 & 19.7 \\
\hline Highly impossible & 4 & 1.7 \\
\hline \multicolumn{3}{|c|}{$\begin{array}{l}\text { Whether or not you agree to sign agreements to not receive } \\
\text { intensive rescuing when at the terminally ill stage* }\end{array}$} \\
\hline Highly possible & 20 & 8.4 \\
\hline Possible & 138 & 57.7 \\
\hline Impossible & 70 & 29.3 \\
\hline Highly impossible & 10 & 4.2 \\
\hline
\end{tabular}

Whether or not you agree to sign agreements to not receive intensive rescuing when your relative is sick and the terminally ill stage*

\begin{tabular}{lrr} 
Highly possible & 6 & 2.5 \\
Possible & 89 & 37.2 \\
Impossible & 124 & 51.9 \\
Highly impossible & 18 & 7.5 \\
\hline
\end{tabular}

*The total number of participants was not 239 , because there were missing data in this item.

CPR, cardiopulmonary resuscitation; DNR, do not resuscitate; EOL, end-of-life.

care in mainland China. Broad propaganda and education are needed to promote the recognition of patients with cancer of palliative care, including expanding media coverage, organising various on-site promotion activities and healthcare providers' advocating. ${ }^{11}$ However, most participants $(75.3 \%)$ already have supportive attitudes towards palliative care after being introduced to it by data collectors. This indicates that palliative care would be accepted among patients with cancer, but does not mean that most patients with cancer would choose palliative care when they arrive at the terminal stage. ${ }^{11}$

When asked about their preferences when signing EOL medical decision agreements, most of the patients with cancer $(77.4 \%)$ claimed that they might sign any EOL medical decision agreements in advance when conscious and competent. Most patients with cancer might agree to

Table 4 Preferences of patients with cancer to EOL care $(\mathrm{n}=239)$

\begin{tabular}{lr}
\hline Preferences to EOL care & N (\%) \\
\hline Preferred place of care & \\
\hline Preferred place of care in the EOL* & \\
\hline Home & $157(65.7)$ \\
General hospital ward & $24(10.0)$ \\
Palliative care unit & $26(10.9)$ \\
Nursing home & $9(3.8)$ \\
Others & $18(7.5)$
\end{tabular}

Whether or not related to medical

insurance ${ }^{\star}$

\begin{tabular}{|cc} 
Yes & $71(29.7)$ \\
No & $72(30.1)$ \\
Not sure & $84(35.2)$ \\
Preferred place of death & \\
Preferred place of death in the EOL * & $189(79.1)$ \\
Home & $24(10.0)$ \\
Hospital & $7(2.9)$ \\
Community care facilities & $18(7.5)$ \\
\hline
\end{tabular}

Whether or not you will come back home

when dying in the hospital ${ }^{*}$

\begin{tabular}{|c|c|}
\hline Yes & $203(84.9)$ \\
\hline No & $33(13.8)$ \\
\hline \multicolumn{2}{|l|}{$\begin{array}{l}\text { The reasons why you are choosing to die at } \\
\text { home }(n=203 \text {, multichoice) } †\end{array}$} \\
\hline Home is the most familiar place & $145(71.4)$ \\
\hline Hoping to be accompanied with families & 157(77.3) \\
\hline $\begin{array}{l}\text { Wishing to die before the tablets of } \\
\text { ancestors }\end{array}$ & $29(14.3)$ \\
\hline Others & $6(3.0)$ \\
\hline
\end{tabular}

The reasons why you are not choosing to

die at home ( $\mathrm{n}=33$, multichoice) $\ddagger$

\begin{tabular}{lc}
$\begin{array}{l}\text { Fear of not having access to adequate } \\
\text { medical care }\end{array}$ & $10(30.3)$ \\
$\begin{array}{l}\text { Hoping to not cause any distress to } \\
\text { families }\end{array}$ & $25(75.8)$ \\
\hline $\begin{array}{l}\text { Fear of families' confusions when dying } \\
\text { Others }\end{array}$ & $3(39.4)$ \\
\end{tabular}

Preferences of truth disclosure

Willingness to know the diagnosis and

prognosis of the disease*

\begin{tabular}{|c|c|}
\hline No & $22(9.2)$ \\
\hline Only want to know the curable disease & $58(24.3)$ \\
\hline Yes, no matter what type of disease it is & $157(65.7)$ \\
\hline \multicolumn{2}{|l|}{$\begin{array}{l}\text { Do you want your doctor to tell your family } \\
\text { or friends about your illness?* }\end{array}$} \\
\hline No & $32(13.4)$ \\
\hline
\end{tabular}




\begin{tabular}{|c|c|}
\hline Preferences to EOL care & $\mathbf{N}(\%)$ \\
\hline Only wishing the families to be informed & $58(24.3)$ \\
\hline Only wishing myself to be informed & $42(17.6)$ \\
\hline $\begin{array}{l}\text { Wishing myself and families to be } \\
\text { informed }\end{array}$ & $106(44.4)$ \\
\hline \multicolumn{2}{|l|}{$\begin{array}{l}\text { Willingness to know the terminal stage of } \\
\text { the disease when coming to the EOL }\end{array}$} \\
\hline No & $26(10.9)$ \\
\hline Only wishing the families to be informed & $36(15.1)$ \\
\hline Only wishing myself to be informed & $71(29.7)$ \\
\hline $\begin{array}{l}\text { Wishing myself and families to be } \\
\text { informed }\end{array}$ & $106(44.4)$ \\
\hline
\end{tabular}

\section{Preferred treatment}

Preferred treatment in the EOL*

Strongly wishing to prolong life expectancy

Wishing to prolong life expectancy

$37(15.5)$

Wishing to improve quality of life $68(28.5)$

$75(31.4)$

Willingness to sign medical decision

agreements in the EOL*

\begin{tabular}{ll} 
No, neither in written nor in oral form & $33(13.8)$ \\
Yes, only in oral form & $40(16.7)$ \\
$\begin{array}{l}\text { Yes, entrusting a family member or agent } \\
\text { to sign after dictation }\end{array}$ & $95(39.7)$ \\
Yes, signing in written form & $64(26.8)$ \\
\hline
\end{tabular}

*The total number of participants was not 239 , because there were missing data in this item.

†Among 203 participants who will come back to home when dying in the hospital.

‡Among 33 participants who will not come back to home when dying in the hospital.

EOL, end-of-life.

not receive intensive rescuing when arriving at the terminally ill stage. This may be because patients with cancer don't want to endure unnecessary suffering or cause any other financial burdens for their families. However, a larger proportion of the participants was unlikely to agree to not receive intensive rescuing when their relatives were in a terminally ill stage. This could be because they may have a stronger willingness to extend their relatives' lives with intensive rescuing in order to avoid regrets. ${ }^{23}$

The most important finding in the present study was that most patients with cancer would like to be cared for at home and die at home. Even when they were cared for at a hospital, the majority of them wished to come back home when dying. These results were consistent with findings from previous research studies. ${ }^{16} 19{ }^{20}{ }^{24}$ However, patients with cancer in Pakistan preferred a hospitalbased death. ${ }^{15}$ Regarding the reasons why they preferred home, 'home is the most familiar place' and 'hoping to be accompanied by families' were listed as the most two common reasons in this study. The EOL stage is the last opportunity for one to say goodbye to their families in the last period of life, which may not only provide one with a valuable opportunity to express emotions but also to alleviate loneliness. ${ }^{25}$ Also, in mainland China, dying at home has a special cultural meaning for both the patients and their families, as the thought of 'Fallen leaves return to the roots-to revert to one's origin' has been embedded in traditional Chinese culture. Some patients in this study even claimed that they wished to die before the tablets of their ancestors. The results revealed that we need to make efforts to facilitate the home-based palliative care in mainland China, so that the patients with cancer can receive quality EOL care at home. At present, home care is usually provided by medical community hospitals and health clinics in mainland China. ${ }^{26}$ To achieve a better EOL quality of life at home, it is necessary to enhance community's capabilities to provide home-based palliative care services in the next decade.

There was also a minor portion of patients with cancer not choosing home as the place of care and death. The most common reason for not choosing home as the place of care was the hope of not causing any burden to families. Additionally, the preferred place of care and death may be influenced by financial issues. ${ }^{27}$ Since there is no specific public medical insurance for EOL care in mainland China, it costs much more to be cared for and die in hospitals or nursing homes. Therefore, some patients with cancer choose to be cared for and die at home partly because of financial burdens. This was consistent with another finding in this study that revealed that nearly a third of the participants' choices were related to medical insurance. Overall, when patients make the decisions regarding their preferred place of care and death, they may take various factors into consideration, such as personal values, family burden, healthcare needs and practical reasons. Individual patients with cancer make a specific decision on where to spend the rest of their life. To better understand the preferences of patients with cancer in terms of place of care and death, every effort should be made to allow their actual concerns to be heard and their unique needs met. ${ }^{24}$

Similar to previous findings, ${ }^{27} 28$ most of the patients with cancer in this study wanted to know their diagnosis or prognosis of the disease regardless of the type of disease. Even when it came to the terminal stage, the majority of them wanted to know their condition. In western countries, it is the patients' right to get a full understanding of their disease, and the physicians have an obligation to inform them. ${ }^{29}$ In mainland China, the patient is possibly the last one in the family to know the diagnosis or prognosis. The physicians tend to inform the families about the patients' condition and seek their advice about whether or not to tell patients with cancer the truth. ${ }^{30}$ Families in mainland China tend to hide conditions from patients with cancer out of protectiveness. ${ }^{31}$ However, the accurate understanding of patients with cancer of their 
illness could allow them to choose care that is congruent with their wishes. ${ }^{32}$ Also, patients who are aware of the incurability of their disease are more likely to prefer hospice care, ${ }^{33}$ which is associated with better EOL care and higher probabilities to die in their preferred place. $^{34}$ The findings in this study provide real thoughts about truth disclosure from the perspectives of patients with cancer. Since discord exists among patient preferences, caregiver preferences and caregiver predictions of patient preferences, it is better for healthcare providers to emphasise the necessities and benefits of informing patients about their illness alongside their families and to include patients in decision-making discussions to avoid medical disputes. ${ }^{35}$

In this study, more than half of the patients with cancer wanted an improved quality of life rather than a longer life expectancy in the EOL. This finding was different from another previous study ${ }^{27}$ conducted in mainland China. This may be caused by the different populations in these two studies. The previous study investigated the EOL care preferences among nursing home residents, while our study investigated the patients with cancer. The patients with cancer are more likely to have a better quality of life in EOL, because they may have experienced suffering and pain during treatments. This finding was consistent with some research ${ }^{1936}$ but was different from other studies ${ }^{1537}$ conducted in other countries. Prioritising a better quality of life or longer life expectancy is not an issue related to right or wrong. It is related to patients' individual views and choices towards EOL care. However, aggressive treatments and life-sustaining treatments that may prolong the life expectancy in the EOL will increase the patients' suffering. From the perspective of healthcare providers, we need to try our best to recommend a better way for patients with cancer to improve their EOL care.

A portion of patients with cancer in this study would not sign any medical agreements in a hypothetical EOL stage, and most of them preferred to entrust a family member or agent to sign medical decision agreements for them. This finding was similar to that which was observed in Macao, China. ${ }^{38}$ In that qualitative study, most participants deferred the decision-making to their families. This may be explained by the diminished sense of autonomy in decision-making under the family-centred model.

\section{Strengths and limitations}

There were several strengths in our study. First, there were few reports on the knowledge, attitudes and preferences of palliative and EOL care issues for mainland Chinese patients with cancer. This study will contribute to an understanding of palliative and EOL care knowledge, attitudes and preferences among patients with cancer as a whole. Additionally, due to the important cultural differences in mainland China and the ever-increasing importance of palliative care and EOL care, a study in the Chinese cancer population was needed.

Limitations also need to be acknowledged. The sample source in this study was limited. The participants were all recruited in one tertiary patient with cancer hospital in one province. Therefore, the opinions of patients with cancer in other areas of mainland China remain to be discussed. In addition, the findings in this study were informed by patients with cancer rather than from the perspectives of terminally ill patients with cancer. The findings may not present the thoughts of terminally ill patients with cancer, as preferences of EOL care change over different stages of diseases. ${ }^{39}{ }^{40}$ We did not evaluate the stage of the patients with cancer, and this would be another limitation. When evaluating participants' preferences of medical decision agreements at the EOL, we did not specify the detailed medical decision agreements. This may lead to different recognitions for different patients. Additionally, some choices involved hypothetical situations, such as the hypothetical terminal stage. Therefore, the choices cannot necessarily present a real situation faced by a terminally ill patient in the future. More research is needed to explore the views and preferences of terminally ill patients with cancer towards EOL care.

\section{CONCLUSIONS}

Patients with cancer had a limited knowledge of palliative care but held supportive attitudes towards it. Most patients with cancer preferred home as the place of care and death in EOL care and also preferred being informed of their diagnosis and prognosis, receiving treatments improving their quality of life and entrusting a family member or agent to sign medical decision agreements. It is essential for healthcare providers to increase the understanding of patients with cancer of palliative care and be aware of the EOL care preferences of patients with cancer, in order to provide support that enables patients with cancer to receive EOL care that is accordant with their wishes, thus improving their EOL experience.

Contributors Study design: QC, KK and YC; data collection: HZ and XX; data analysis: $Q C$ and $Y D$; interpretation of data and critical revision of the manuscript for important intellectual content: QC, YD, YC and JX.

Funding The authors have not declared a specific grant for this research from any funding agency in the public, commercial or not-for-profit sectors.

Competing interests None declared.

Patient and public involvement Patients and/or the public were not involved in the design, conduct, reporting or dissemination plans of this research.

Patient consent for publication Not required.

Ethics approval The study had been approved by the institutional review board of behavioural and nursing research in School of Nursing of Central South University (12019014).

Provenance and peer review Not commissioned; externally peer reviewed.

\section{Data availability statement Data are available upon reasonable request.}

Open access This is an open access article distributed in accordance with the Creative Commons Attribution Non Commercial (CC BY-NC 4.0) license, which permits others to distribute, remix, adapt, build upon this work non-commercially, and license their derivative works on different terms, provided the original work is properly cited, appropriate credit is given, any changes made indicated, and the use is non-commercial. See: http://creativecommons.org/licenses/by-nc/4.0/.

ORCID iD

Yongyi Chen http://orcid.org/0000-0002-9079-1496 


\section{REFERENCES}

1 Feng R-M, Zong Y-N, Cao S-M, et al. Current cancer situation in China: good or bad news from the 2018 Global Cancer Statistics? Cancer Commun 2019;39:22.

2 Chen W, Zheng R, Baade PD, et al. Cancer statistics in China, 2015. CA Cancer J Clin 2016;66:115-32.

3 Ning $\mathrm{XH}$. Hospice and palliative care in mainland China: history, current status and challenges. Chin Med Sci J 2018;33:199-203.

4 The Economist intelligence unit. quality of death index, 2015. Available: https://perspectives.eiu.com/healthcare/2015-qualitydeath-index

5 National Health Commission. Notice on issuing practice guidelines of palliative care (trial), 2017. Available: http://www.nhc.gov.cn/yzygj/ s3593/201702/3ec857f8c4a244e69b233ce2f5f270b3.shtml

6 National Health Commission. Notice on issuing the basic standards and management norms of palliative care centers (trial), 2017. Available: http://www.nhc.gov.cn/yzygj/s3593/201702/2f50fdc62fa8 4cdd9d9a09d5162a661f.shtml

7 National Health Commission. Notice on the issueing guidelines for the reform and development of nursing services, 2018. Available: http://www.nhc.gov.cn/yzygj/s7659/201807/1a71c7bea4a04d5f82d1 aea262ab465e.shtml

8 State Council of the central Committee of the Communist Party of China. medium and long-term national plan for population aging, 2019. Available: http://www.gov.cn/xinwen/2019-11/21/content_ 5454347.htm

9 Chen T-R, Hu W-Y, Two S-N, et al. What influences the willingness of cancer patients to receive hospice palliative care at end of life? Jpn J Clin Oncol 2019;49:361-6.

10 Cagle JG, Kovacs PJ. Informal caregivers of cancer patients: perceptions about preparedness and support during hospice care. $J$ Gerontol Soc Work 2011;54:92-115.

11 Ni K, Gong Y, Li F, et al. Knowledge and attitudes regarding hospice care among outpatients and family members in two hospitals in China. Medicine 2019;98:e15230.

$12 \mathrm{Li} \mathrm{T}$, Pei X, Chen X, et al. Identifying end-of-life preferences among Chinese patients with cancer using the heart to heart card game. Am $J$ Hosp Palliat Care 2021;38:1049909120917361.

13 Romo RD, Allison TA, Smith AK, et al. Sense of control in end-of-life decision-making. J Am Geriatr Soc 2017;65:e70-5.

14 Hunt KJ, Shlomo N, Addington-Hall J. End-of-life care and achieving preferences for place of death in England: results of a populationbased survey using the VOICES-SF questionnaire. Palliat Med 2014;28:412-21.

15 Zafar W, Hafeez $\mathrm{H}$, Jamshed A, et al. Preferences regarding disclosure of prognosis and end-of-life care: a survey of cancer patients with advanced disease in a lower-middle-income country. Palliat Med 2016;30:661-73

16 Loh AZH, Tan JSY, Jinxuan T, et al. Place of care at end of life: what factors are associated with patients' and their family members' preferences? Am J Hosp Palliat Care 2016;33:669-77.

17 Hirano H, Shimizu C, Kawachi A, et al. Preferences regarding end-oflife care among adolescents and young adults with cancer: results from a comprehensive multicenter survey in Japan. J Pain Symptom Manage 2019;58:235-43.

18 Miccinesi G, Bianchi E, Brunelli C, et al. End-of-life preferences in advanced cancer patients willing to discuss issues surrounding their terminal condition. Eur J Cancer Care 2012;21:623-33.

19 Waller A, Sanson-Fisher R, Nair BR, et al. Preferences for end-of-life care and decision making among older and seriously ill inpatients: a cross-sectional study. J Pain Symptom Manage 2020;59:187-96.
20 Shen MJ, Prigerson HG, Ratshikana-Moloko M, et al. Illness understanding and end-of-life care communication and preferences for patients with advanced cancer in South Africa. J Glob Oncol 2018;4:1-9.

21 Alyami HM, Chan RJ, New K. End-Of-Life care preferences for people with advanced cancer and their families in intensive care units: a systematic review. Support Care Cancer 2019;27:3233-44.

22 Huang Q-S. A review on problems of China's hospice care and analysis of possible solutions. Chin Med J 2015;128:279-81.

23 Malhotra C, Farooqui MA, Kanesvaran R, et al. Comparison of preferences for end-of-life care among patients with advanced cancer and their caregivers: a discrete choice experiment. Palliat Med 2015;29:842-50.

24 Tang ST. When death is imminent: where terminally ill patients with cancer prefer to die and why. Cancer Nurs 2003;26:245-51.

25 Yeh S-T, Ng Y-Y, Wu S-C. Hospital and patient characteristics regarding the place of death of hospitalized impending death patients: a multilevel analysis. Int J Environ Res Public Health 2019;16:4609.

26 Lu Y, Gu Y, Yu W. Hospice and palliative care in China: development and challenges. Asia Pac J Oncol Nurs 2018;5:26-32.

$27 \mathrm{Ni}$ P, Zhou J, Wang ZX, et al. Advance directive and end-of-life care preferences among nursing home residents in Wuhan, China: a cross-sectional study. J Am Med Dir Assoc 2014;15:751-6.

28 Jiang Y, Liu C, Li J-Y, et al. Different attitudes of Chinese patients and their families toward truth telling of different stages of cancer. Psychooncology 2007;16:928-36.

29 Fallowfield L, Jenkins V. Communicating sad, bad, and difficult news in medicine. Lancet 2004;363:312-9.

30 Hahne J, Liang T, Khoshnood K, et al. Breaking bad news about cancer in China: concerns and conflicts faced by doctors deciding whether to inform patients. Patient Educ Couns 2020;103:286-91.

31 Wang D-can, Guo C-bin, Peng X, et al. Is therapeutic non-disclosure still possible? A study on the awareness of cancer diagnosis in China. Support Care Cancer 2011;19:1191-5.

32 Yoo SH, Lee J, Kang JH, et al. Association of illness understanding with advance care planning and end-of-life care preferences for advanced cancer patients and their family members. Support Care Cancer 2020;28:2959-67.

33 Mack JW, Walling A, Dy S, et al. Patient beliefs that chemotherapy may be curative and care received at the end of life among patients with metastatic lung and colorectal cancer. Cancer 2015;121:1891-7.

34 Wright AA, Keating NL, Ayanian JZ, et al. Family perspectives on aggressive cancer care near the end of life. JAMA 2016;315:284-92.

35 Shin DW, Cho J, Kim SY, et al. Discordance among patient preferences, caregiver preferences, and caregiver predictions of patient preferences regarding disclosure of terminal status and endof-life choices. Psychooncology 2015;24:212-9.

36 Chung RY-N, Wong EL-Y, Kiang N, et al. Knowledge, attitudes, and preferences of advance decisions, end-of-life care, and place of care and death in Hong Kong. a population-based telephone survey of 1067 adults. J Am Med Dir Assoc 2017;18:367.e19-367.e27.

37 Tan WS, Bajpai R, Ho AHY, et al. Retrospective cohort analysis of real-life decisions about end-of-life care preferences in a Southeast Asian country. BMJ Open 2019;9:e024662.

38 Ho S-W, Sanders GF. Preferences on end-of-life decisions among older Chinese in Macau. J Transcult Nurs 2015;26:741-3.

39 Agar M, Currow DC, Shelby-James TM, et al. Preference for place of care and place of death in palliative care: are these different questions? Palliat Med 2008;22:787-95.

40 Ali M, Capel M, Jones G, et al. The importance of identifying preferred place of death. BMJ Support Palliat Care 2019;9:84-91. 